\title{
Mutants of Streptococcus gordonii Challis over-producing glucosyltransferase
}

\author{
R. J. HAISMAN and H. F. JENKINSON* \\ Department of Oral Biology and Oral Pathology, University of Otago, PO Box 647, Dunedin, New Zealand
}

(Received 21 August 1990; revised 29 October 1990; accepted 16 November 1990)

\begin{abstract}
Two mutants of Streptococcus gordonii which over-produced extracellular polysaccharide when grown on sucrosecontaining medium were isolated after mutagenesis of strain Challis with ethyl methanesulphonate. The mutants, designated strains $\mathrm{OB} 20$ and $\mathrm{OB} 30$, expressed 2.6-fold and 4.7-fold respectively more glucosyltransferase (GTF) activities than the wild-type strain. Transformation experiments suggested that the two mutants carried different mutations, denoted $g t f-20$ and $g t f-30$. A double mutant ( $g t f-20 g t f-30)$ was constructed and this strain produced 6-4-fold more GTF. Enzymes from wild-type and mutant strains were biochemically indistinguishable and they synthesized structurally identical glucans. Increasing the $\mathrm{Na}^{+}$concentration of the bacterial growth medium reduced GTF production in all strains by about $60 \%$. Tween 80 also inhibited enzyme production and more specifically reduced GTF synthesis by the mutants. The mutations $g t f-20$ and $g t f-30$ appear to define separate genetic loci involved in regulating expression of GTF activity in $S$. gordonii.
\end{abstract}

\section{Introduction}

The oral streptococci produce a variety of glucosyltransferase (GTF; EC 2.4.1.5) and fructosyltransferase (FTF; EC 2.4.1.10) enzymes that polymerize the hydrolytic products of sucrose into glucans or fructans (reviewed by Walker \& Jacques, 1987). Expression of GTF and FTF enzymes and synthesis of polysaccharides by oral bacteria are important in the formation and maturation of dental plaque, which elicits caries and periodontal disease. Production of GTF and FTF by Streptococcus mutans, a principal aetiological agent in caries, is known to contribute to its virulence. Mutants constructed by insertion mutagenesis and deficient in GTF showed reduced sucrose-dependent colonization of smooth surfaces (Sato et al., 1987); mutants deficient in FTF showed reduced ability to cause caries in a rat model (Shroeder et al., 1989).

Streptococcus gordonii and Streptococcus sanguis are amongst the bacterial species believed to be primary colonizers of the clean tooth surface (Gibbons \& van Houte, 1975). Studies, analogous to those described above for $S$. mutans, on the roles of GTF and FTF in $S$.

\footnotetext{
* Author for correspondence (electronic mail address: EOBMRC@NZ.AC.OTAGO).

Abbreviations: CRS, Congo red/sucrose; FTF, fructosyltransferase; GTF, glucosyltransferase; PAS, periodic acid/Schiff; Rif ${ }^{\mathbb{R}}$, rifampicin resistant; Str $^{\mathbf{R}}$, streptomycin resistant.
}

gordonii adherence have not yet been done, nevertheless there is evidence that GTF production may be important for colonization by $S$. gordonii. Extracellular polysaccharide synthesis was correlated with the ability of $S$. gordonii strains to adhere to smooth surfaces (Westergren, 1978), and glucan production may be involved in the development of $S$. gordonii endocarditis (Scheld et al., 1978). Thus the ability to regulate production of GTF may be important for virulence of $S$. gordonii. S. gordonii strain NCTC 7865 (ATCC 10558) and $S$. gordonii strain Challis, until recently both classified as $S$. sanguis (Kilian et al., 1989), each produce GTF which in the undegraded form appears to run as a single band on SDS-PAGE with an approximate molecular mass of $174 \mathrm{kDa}$ (Grahame \& Mayer, 1985; Buchan \& Jenkinson, 1990). This band becomes degraded both extracellularly in culture $\mathrm{Bu}$ chan \& Jenkinson, 1990) and during storage in vitro (Grahame \& Mayer, 1984) to a $155 \mathrm{kDa}$ enzymically active product. Other multiple active forms of the enzyme exist in some preparations and these arise through aggregation and/or breakdown of the $174 \mathrm{kDa}$ polypeptide (Grahame \& Mayer, 1984). The $174 \mathrm{kDa}$ and $155 \mathrm{kDa}$ forms of the enzyme each synthesize a structurally similar glucan (Grahame \& Mayer, 1985) which is partly water-insoluble (Buchan \& Jenkinson, 1990).

Production of GTF by $S$. gordonii is affected by extracellular $\mathrm{Na}^{+}$concentration (Keevil et al., 1984; 
Buchan \& Jenkinson, 1990) and is inhibited by ionophores (West et al., 1987). Tween 80 inhibits production of GTF enzyme in S. gordonii Challis and in several other oral streptococcal species (Buchan \& Jenkinson, 1990). Both $\left[\mathrm{Na}^{+}\right]$and Tween 80 are thought to influence enzyme secretion through perturbation of the cell membrane. However, the major inhibitory effect of Tween 80 appears to be at the level of synthesis of GTF (Buchan \& Jenkinson, 1990). Recent work has shown that GTF production by $S$. gordonii Challis may be transcriptionally controlled and subject to a phase switch (Tardif $e t$ al., 1989). This paper describes the isolation and characterization of $S$. gordonii mutants that over-express GTF. Evidence is presented which suggests that there are at least two distinct loci involved in regulation of GTF production in this organism.

\section{Methods}

Bacterial strains and media. Strains of S. gordonii used in this work are listed in Table 1. Bacteria were routinely cultured on BHYN agar (Jenkinson, 1986) at $37^{\circ} \mathrm{C}$ in a BBL Gas-Pak System (BBL Microbiology Systems). Polysaccharide production by colonies was detected with Congo Red/sucrose (CRS) agar which contained $\left(1^{-1}\right)$ : Trypticase Soy Broth (TSB; BBL Microbiology Systems), $30 \mathrm{~g}$; Neopeptone (Difco), $5 \mathrm{~g}$; Yeast Extract (Difco), $5 \mathrm{~g}$; sucrose, $10 \mathrm{~g}$; Congo Red (BDH), $30 \mathrm{mg}$; agar, $15 \mathrm{~g}$. Liquid cultures for polysaccharide production were grown in TSB $\left(30 \mathrm{~g} \mathrm{l}^{-1}\right)$ containing Yeast Extract $\left(5 \mathrm{~g}^{-1}\right)$ and sucrose $\left(8 \mathrm{~g}^{-1}\right)$. Cultures for measurement of GTF activity and for preparation of extracellular proteins were grown in defined medium containing glucose $\left(8 \mathrm{~g} \mathrm{l}^{-1}\right)$ (Jenkinson, 1986). This

Table 1. Strains of S. gordonii

\begin{tabular}{|c|c|c|}
\hline Strain & Genotype & Source or construction $\dagger$ \\
\hline OB11-Challis & Wild-type & $\begin{array}{l}\text { Laboratory stock (from } \\
\text { F. L. Macrina) }\end{array}$ \\
\hline OB11.1 & str-1 & Spontaneous $\mathrm{Str}^{R}$ mutant of $\mathrm{OB} 11$ \\
\hline DL1-Challis* & Wild-type & $\begin{array}{l}\text { Laboratory stock (from } \\
\text { S. Hamada) }\end{array}$ \\
\hline OB20 & $g t f-20$ & $\begin{array}{l}\text { EMS mutagenesis of } \mathrm{OB} 11 \text { (this } \\
\text { work) }\end{array}$ \\
\hline $\mathrm{OB} 20.2$ & $g t f-20$ str -2 & Spontaneous $\operatorname{Str}^{R}$ mutant of OB20 \\
\hline $\mathrm{OB} 20.3$ & gtf-20 rif-I & Spontaneous Rif ${ }^{\mathbb{R}}$ mutant of OB20 \\
\hline OB20.4 & $g t f-20$ str -2 & $\begin{array}{l}\text { Transformation (OB20.2 DNA } \rightarrow \\
\text { DL1) }\end{array}$ \\
\hline OB30 & $g t f-30$ & $\begin{array}{l}\text { EMS mutagenesis of OB11 (this } \\
\text { work) }\end{array}$ \\
\hline OB30.2 & $g t f-30$ str-3 & Spontaneous Str ${ }^{R}$ mutant of OB30 \\
\hline OB30.4 & $g t f-30$ str-3 & $\begin{array}{l}\text { Transformation (OB30.2 DNA } \rightarrow \\
\text { DL1) }\end{array}$ \\
\hline OBD3 & $g t f-20 \mathrm{gtf}-30$ str-2 & $\begin{array}{l}\text { Transformation (OB20.2 DNA } \rightarrow \\
\text { OB30) }\end{array}$ \\
\hline
\end{tabular}

* The two wild-type Challis strains are distinguished because they had different lineages and cells of strain DL1-Challis were more competent for transformation.

† F. L. Macrina, Virginia Commonwealth University, Richmond, VA, USA; S. Hamada, Osaka University, Suita, Osaka, Japan. medium was modified to contain a high $\left[\mathrm{Na}^{+}\right] /\left[\mathrm{K}^{+}\right]$ratio as previously described (Buchan \& Jenkinson, 1990). Tween 80 (Serva Feinbiochemica) was incorporated into media at $0.05 \%(\mathrm{v} / \mathrm{v})$ final concentration.

Mutagenesis. Ethyl methanesulphonate (EMS; Sigma; $0.2 \mathrm{ml}$ ) was added to an exponential-phase culture of $S$. gordonii $\mathrm{OB} 11-\mathrm{Challis}$ in BHY medium (Jenkinson, 1986) $\left(10 \mathrm{ml}\right.$ containing about $3 \times 10^{8}$ cells $\mathrm{ml}^{-1}$ ) which was incubated for $1 \mathrm{~h}$ at $37^{\circ} \mathrm{C}$. The EMS treatment resulted in about $95 \%$ killing as estimated from agar plate colony counts of culture samples taken before and after incubation with mutagen. The cells were harvested by centrifugation $(6000 \mathrm{~g}, 10 \mathrm{~min}$, $20^{\circ} \mathrm{C}$ ), suspended in BHY medium $(3 \mathrm{ml})$ and sonicated briefly $(3 \times 5 \mathrm{~s}, 50 \mathrm{~W}$, Dawe Instruments Soniprobe) to break chains. The bacteria were collected by centrifugation as before and washed by two cycles of suspension in BHY medium and centrifugation. The final cell pellet was suspended in $1 \mathrm{ml} \mathrm{BHY}$ medium, apportioned into ten tubes each containing pre-warmed BHY medium $(10 \mathrm{ml})$, and cultures were incubated for $3 \mathrm{~h}$ at $37^{\circ} \mathrm{C}$. Portions of the cultures were suitably diluted and plated onto CRS agar to give 300-600 colonies per plate. Colonies with pale colour or unusual morphologies were selected and purified by subculture on CRS agar. From about 30000 colonies screened, 37 were initially selected, and of these only eight showed stable colony morphology on repeated subculture. Spontaneous streptomycin-resistant $\left(\mathrm{Str}^{\mathrm{R}}\right)$ or rifampicin-resistant (Rif $\left.{ }^{\mathrm{R}}\right)$ mutants were isolated by plating portions $(0 \cdot 1 \mathrm{ml})$ of culture containing $10^{7}$ cells onto the surface of BHYN agar containing streptomycin $\left(0.5 \mathrm{mg} \mathrm{ml}^{-1}\right)$ or rifampicin $\left(25 \mu \mathrm{g} \mathrm{ml}^{-1}\right)$.

Transformation. DNA was extracted from $S$. gordonii and purified as described by Jenkinson (1987). Competent cells were prepared by the method of Rollins et al. (1985). Approximately $2 \times 10^{6}$ cells in the exponential growth phase in BHY medium containing $1 \%(w / v)$ glucose and $1 \%(\mathrm{v} / \mathrm{v})$ heat-inactivated $\left(60^{\circ} \mathrm{C}, 30 \mathrm{~min}\right)$ foetal calf serum were incubated with DNA (approx. $1 \mu \mathrm{g}$ ) for $4 \mathrm{~h}$ at $37^{\circ} \mathrm{C}$. Portions were suitably diluted in BHY medium and transformants were selected on BHYN agar or on CRS agar containing streptomycin $\left(0.5 \mathrm{mg} \mathrm{ml}^{-1}\right)$ or rifampicin $\left(25 \mu \mathrm{g} \mathrm{m}^{-1}\right)$.

Preparation of extracellular proteins. Late-exponential-phase cultures growing in glucose defined medium were centrifuged $\left(5000 \mathrm{~g}, 4^{\circ} \mathrm{C}\right.$, $10 \mathrm{~min}$ ), proteins were precipitated from cell-free supernatants with $\left(\mathrm{NH}_{4}\right)_{2} \mathrm{SO}_{4}$, and samples were prepared for GTF assay or for electrophoresis as previously described (Buchan \& Jenkinson, 1990). The amount of protein secreted into the culture medium was determined by growing cells in defined medium with glucose and L-[U${ }^{14} \mathrm{C}$ ] leucine (Buchan \& Jenkinson, 1990). Protein concentration was measured by the Lowry method with bovine albumin as standard.

Assay of enzyme activity. GTF was assayed and the $K_{\mathrm{m}}$ for sucrose was determined using $\left[\mathrm{U}^{-14} \mathrm{C}\right]$ sucrose as described by Buchan \& Jenkinson (1990). One unit (U) of enzyme activity is defined as the amount of enzyme that catalyses the incorporation of $1 \mu \mathrm{mol}$ sucrose into methanol-precipitable material $\mathrm{min}^{-1}$ at $37^{\circ} \mathrm{C}$.

SDS-PAGE. Samples were electrophoresed through $7.5 \%(\mathrm{w} / \mathrm{v})$ acrylamide gels containing $0.1 \%(w / v)$ SDS by the method of Laemmli \& Favre (1973). Polypeptide bands were stained with silver nitrate (Merril et al., 1981). Molecular masses of proteins were estimated by relating their migration distances to those of the following markers (from Sigma) : $\alpha_{2}$ macroglobulin $(180 \mathrm{kDa}), \beta$-galactosidase $(116 \mathrm{kDa})$, fructose-6-phosphate kinase $(84 \mathrm{kDa})$, pyruvate kinase $(58 \mathrm{kDa})$, fumarase (48.5 kDa), lactic dehydrogenase ( $36.5 \mathrm{kDa})$ and triosephosphate isomerase $(26.6 \mathrm{kDa})$. To visualize GTF activity after SDSPAGE, gels were incubated with $10 \mathrm{~mm}$-sodium acetate/acetic acid (pH 6) containing $1 \%(\mathrm{w} / \mathrm{v})$ sucrose and $1 \%(\mathrm{v} / \mathrm{v})$ Triton $\mathrm{X}-100$ (Russell, 1979) then stained with periodic acid/Schiff (PAS) reagent (Buchan \& Jenkinson, 1990). Stained bands of protein or polysaccharide were quantified by scanning the gels with a laser densitometer. 
Table 2. Production of glucan, GTF and extracellular protein in cultures of wild-type S. gordonii and gtf mutant derivatives

Experiments were repeated at least three times and assays were run in duplicate or triplicate. The results are shown \pm SEM.

\begin{tabular}{|c|c|c|c|c|c|c|}
\hline Strain & $\begin{array}{l}\text { Extracellular glucan* } \\
\text { [mg (mg dry wt } \\
\left.\text { cells })^{-1}\right]\end{array}$ & $\begin{array}{c}\text { Whole culture } \dagger \\
\text { GTF activity } \\
\left(\mathrm{mU} \mathrm{ml} \mathrm{m}^{-1}\right)\end{array}$ & $\begin{array}{c}\text { Culture } \\
\text { supernatant } \dagger \\
\text { GTF activity } \\
\left.(\mathrm{mU} \mathrm{ml})^{-1}\right)\end{array}$ & $\begin{array}{l}\text { Culture } \\
\text { supernatant } \dagger \\
\text { protein } \\
\left(\mu \mathrm{g} \mathrm{ml}^{-1}\right)\end{array}$ & $\begin{array}{c}+0.05 \% \text { Tween } 80 \dagger \\
\text { culture supernatant } \\
\text { GTF activity } \S \\
\left.(\mathrm{mU} \mathrm{ml})^{-1}\right)\end{array}$ & $\begin{array}{c}+ \text { high }\left[\mathrm{Na}^{+}\right] /\left[\mathrm{K}^{+}\right] \ddagger \\
\text { culture supernatant } \\
\text { GTF activity } \S \\
\left.(\mathrm{mU} \mathrm{ml})^{-1}\right)\end{array}$ \\
\hline OB11-Challis & $0.26 \pm 0.04$ & $34 \cdot 1 \pm 2 \cdot 7$ & $31 \cdot 2 \pm 1 \cdot 6$ & $11 \cdot 2 \pm 3 \cdot 4$ & $18 \cdot 0 \pm 1 \cdot 1(58)$ & $12.4 \pm 0.9(40)$ \\
\hline OB20 & $0.56 \pm 0.08$ & $88 \cdot 1 \pm 4 \cdot 4$ & $78 \cdot 1 \pm 4 \cdot 7$ & $14 \cdot 2 \pm 3 \cdot 7$ & $15.9 \pm 0.8(20)$ & $35.6 \pm 1.8(46)$ \\
\hline OB30 & $1.53 \pm 0.21$ & $159 \cdot 1 \pm 7.9$ & $127 \cdot 1 \pm 8 \cdot 4$ & $10 \cdot 2 \pm 3 \cdot 2$ & $20.8 \pm 0.4(16)$ & $47 \cdot 8 \pm 2 \cdot 4(38)$ \\
\hline OBD3 & $1.99 \pm 0.29$ & $216 \cdot 2 \pm 11 \cdot 8$ & $181 \cdot 2 \pm 9 \cdot 1$ & ND & $51 \cdot 7 \pm 2.6(28)$ & $70 \cdot 3 \pm 4 \cdot 5$ \\
\hline
\end{tabular}

ND, Not determined.

* Cultures grown in TSB medium containing sucrose to early stationary phase $\left(0.9 \mathrm{mg}\right.$ dry wt $\left.\mathrm{ml}^{-1}\right)$.

$\dagger$ Cultures grown in defined medium with glucose to early stationary phase $\left(1.5 \mathrm{mg}\right.$ dry wt $\left.\mathrm{ml}^{-1}\right)$.

$\ddagger$ Cultures grown in high $\left[\mathrm{Na}^{+}\right] /\left[\mathrm{K}^{+}\right]$defined medium with glucose to early stationary phase $\left(1.5 \mathrm{mg}\right.$ dry wt $\left.\mathrm{ml}^{-1}\right)$.

$\S$ Figures in parentheses are percentage activities of control culture supernatant GTF activities (column 4).

Glucan production. Extracellular polysaccharides produced by cultures of $S$. gordonii were precipitated from cell-free culture medium with ethanol $(80 \%, v / v$, final concn), collected on filters and dried to constant weight (Buchan \& Jenkinson, 1990). Polysaccharide hydrolysates were analysed by thin-layer or paper chromatography for component sugars as described previously (Buchan \& Jenkinson, 1990). For preparation of glucans for chemical analysis, culture fluid protein (containing approx. $0.4 \mathrm{mg}$ protein and $4 \mathrm{U}$ GTF) was incubated in $10 \mathrm{~mm}$-sodium acetate/acetic acid buffer $\mathrm{pH} 6.0$ containing $15 \mathrm{~mm}$ $\mathrm{NaF}, 3 \mathrm{~mm}-\mathrm{NaN}_{3}$, and sucrose $(5 \% \mathrm{w} / \mathrm{v})(20 \mathrm{ml})$ for $3 \mathrm{~d}$ at $37^{\circ} \mathrm{C}$. The viscous suspension was then dialysed against deionized water containing $3 \mathrm{~mm}-\mathrm{NaN}_{3}$ for $16 \mathrm{~h}$ at $4{ }^{\circ} \mathrm{C}$ and freeze-dried.

Periodate oxidation. Glucans $(3 \mathrm{mg})$ or commercial $\mathrm{T} 10$ dextran (Sigma) were added to triplicate bottles containing $0.015 \mathrm{M}$-sodium periodate $(5 \mathrm{ml})$ and mixtures were shaken in the dark for $48 \mathrm{~h}$ at $4{ }^{\circ} \mathrm{C}$. Controls containing sodium periodate and sodium iodate without glucan were included. Formic acid produced was measured by titration with $8.77 \times 10^{-4} \mathrm{M}-\mathrm{NaOH}$, and periodate consumption was estimated from $A_{222.5}$ measurements (Hay et al., 1965).

${ }^{13} \mathrm{C} \mathrm{NMR}$. Glucans $(30 \mathrm{mg}$ ) were suspended in dimethylsulphoxide $(1 \mathrm{ml})$ at $75^{\circ} \mathrm{C}$. Samples (in $10 \mathrm{~mm}$ diam. tubes) were analysed in a VXR 300 spectrometer for $16 \mathrm{~h}$ at $75^{\circ} \mathrm{C}$. Parameters of pulse sequence were: pulse width $11.8-17 \mu \mathrm{s}$, acquisition time $0.624 \mathrm{~s}$, delay $1.9 \mathrm{~s}$; spectra were decoupled and the samples were referenced to dimethylsulphoxide. Signal assignments were made according to Colson et al. (1979) and Seymour et al. (1980).

\section{Results}

\section{Isolation of mutants}

As a result of mutagenesis of $S$. gordonii OB11-Challis with EMS and screening on CRS agar for extracellular polysaccharide mutants (see Methods), two strains designated $\mathrm{OB} 20$ and $\mathrm{OB} 30$ were selected for further study. Colonies of the wild-type strains OB11-Challis or DL1-Challis after $36 \mathrm{~h}$ incubation of plates at $37^{\circ} \mathrm{C}$ were orange-red, round, $1-1.5 \mathrm{~mm}$ diameter, and had a soft texture (they were easily smeared with a wire inoculating loop). Colonies of strains OB20 and OB30 were similar in size but were pink or pale-pink respectively, were hard in texture, and to be removed from the agar they needed to be dug out with a wire. Strains OB20 and OB30 were grown in TSB/sucrose medium and were found to produce $2 \cdot 2$-fold and $5 \cdot 9$-fold respectively more extracellular polysaccharide than strain OB11-Challis (Table 2). The polysaccharides produced by all strains were analysed by thin-layer chromatography and by paper chromatography of partial or complete acid hydrolysates. Only glucose, or oligosaccharides of the isomaltose series were present, indicating that only glucan and no fructan was produced under the growth conditions (see also Buchan \& Jenkinson, 1990).

Strains $O B 20$ and $O B 30$ had growth rates in the exponential phase similar to that of strain $\mathrm{OB} 11$-Challis in glucose defined medium $\left(t_{\mathrm{d}}\right.$ about $\left.50 \mathrm{~min}\right)$. All strains had similar sugar fermentation profiles (see Kilian et al., 1989). Strain OB30 formed shorter chains of cells (average two to four per chain) compared with strains $\mathrm{OB} 20$ and $\mathrm{OB} 11-\mathrm{Ch}$ allis (average six to eight per chain). The glucan-overproducing colony phenotypes of strains OB20 and OB30 were stable over repeated subcultures on CRS medium.

\section{Genetic analysis}

Spontaneous $\operatorname{Str}^{\mathrm{R}}$ derivatives of strains $\mathrm{OB} 20$ and $\mathrm{OB} 30$ were isolated as described in Methods. DNAs were prepared from these strains and used to transform strain DL1-Challis to streptomycin resistance on CRS agar. Colonies were scored for polysaccharide over-producing phenotype. The mutation in strain OB20 (denoted $g t f-20$ ) was cotransformed with $\operatorname{Str}^{\mathrm{R}}$ at a frequency of $0.1 \%$ $(2 / 2060)$ while the mutation in strain OB30 (denoted $g t f$ 30) was cotransformed with $\operatorname{Str}^{\mathrm{R}}$ at a higher frequency of nearly $10 \%(103 / 1050)$. The $\operatorname{Str}^{\mathrm{R}}$ derivatives (designated OB20.4 and OB30.4, Table 1), isogenic with DL1-Challis 


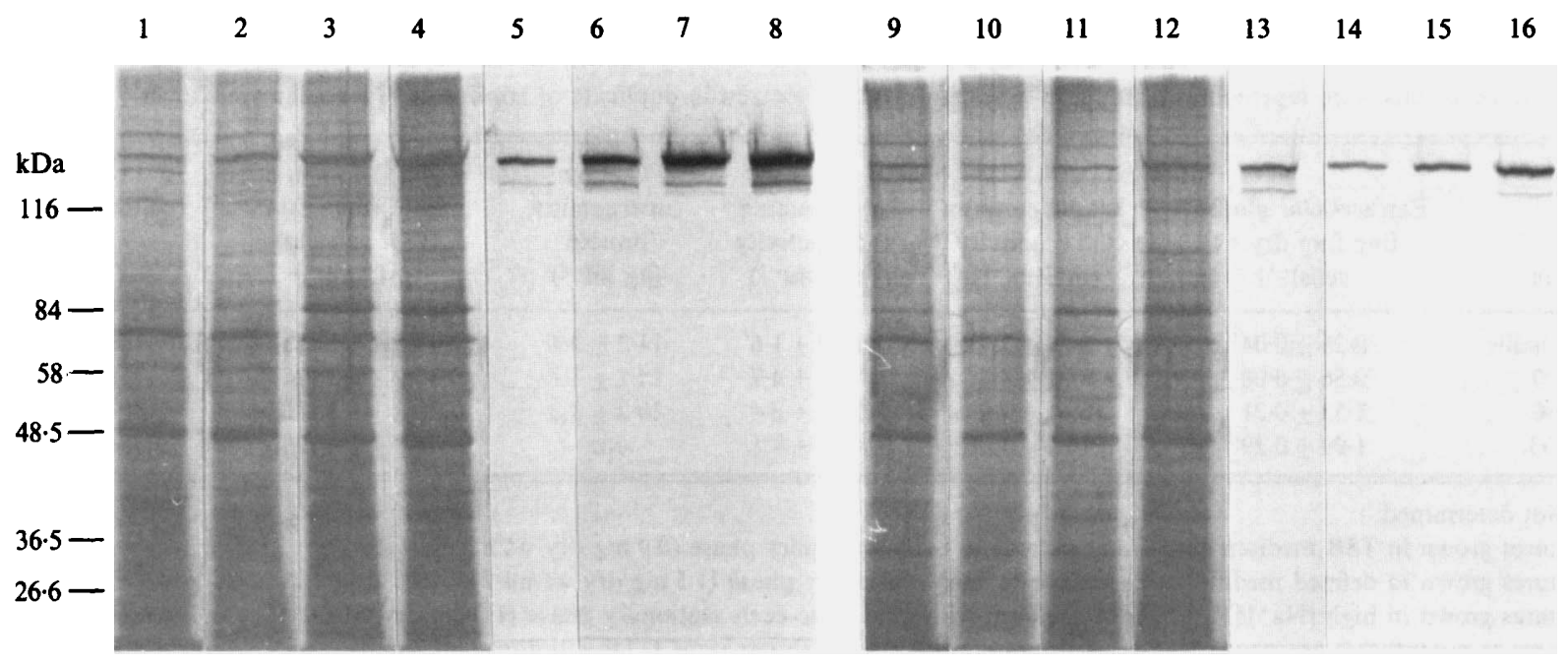

Fig. 1. SDS-PAGE profiles of extracellular proteins stained with silver nitrate (lanes 1-4 and 9-12) or stained for GTF activity with PAS reagent (lanes 5-8 and 13-16) from wild-type and mutant strains of $S$. gordonii. Lanes 1, 5, 9 and 13, strain OB11 (wild-type); lanes $2,6,10$ and 14 , strain OB20; lanes 3, 7, 11 and 15, strain OB30; lanes 4, 8, 12 and 16, strain OBD3. Lanes 1 to 8 contained proteins from cultures grown in defined medium with glucose; lanes 9 to 16 contained proteins from cultures grown in glucose defined medium containing $0.05 \%(\mathrm{v} / \mathrm{v})$ Tween 80 . The positions of molecular mass markers are shown for reference.

and harbouring either $g t f-20$ or $g t f-30$, were phenotypically identical to the original mutants OB20 and OB30.

To determine if mutations $g t f-20$ and $g t f-30$ were at different sites on the chromosome, strain OB30 (streptomycin sensitive) was transformed to streptomycin resistance with DNA prepared from strain OB20.2 (Table 1$)$. About $5 \%(55 / 1020)$ of transformants grew as virtually colourless colonies on CRS medium compared with the background of pale-pink colonies of recipient strain OB30. In addition about $5 \%$ of the colonies were orange-red coloured (wild-type). Several of the colourless colonies were purified. One strain (designated OBD3, Table 1), which was representative of all those tested, produced 7.6-fold more extracellular polysaccharide from sucrose than did strain OB11-Challis (Table 2). This increased production of glucan by strain OBD3, over and above that produced by either OB20 or OB30, suggested that OBD3 carried both mutations $g t f-20$ and $g t f-30$. To confirm this genetically, DNA was prepared from the rifampicin-resistant $\left(\mathrm{Rif}^{\mathrm{R}}\right)$ strain $\mathrm{OB} 20.3$ (Table 1) and used to transform strain OBD3 to rifampicin resistance. Approximately 5000 colonies on CRS medium were screened and no orange-red coloured (wild-type) colonies could be observed amongst the palepink or colourless transformants. These results suggested that the mutations $g t f-20$ and $g t f-30$ were at different loci.

\section{GTF production}

In defined medium containing glucose, strains $\mathrm{OB} 20$, OB30 and OBD3 all produced more GTF than strain
OB11-Challis (Table 2). Roughly speaking the overproduction of extracellular polysaccharide by these strains as described above could be accounted for by proportional increases in total culture GTF activities (Table 2). For each strain, $80 \%$ or more of the total culture GTF activity was present in the cell-free culture supernatant (Table 2).

Measurement of cell-free culture supernatant protein concentrations showed that OB20 and OB30 did not secrete more total protein than OB11-Challis (Table 2). In the wild-type strain GTF accounted for $<10 \%$ of total extracellular protein. Culture supernatant proteins of the various strains were compared by SDS-PAGE and gels were stained either with silver nitrate, or for GTF activity with PAS reagent (see Methods). Overproduction of a polypeptide band of approximate molecular mass $174 \mathrm{kDa}$ corresponding to GTF was visible in stained protein profiles from strains OB20, OB30 and OBD3 (Fig. 1). Strain OB30 (and OBD3) also secreted increased amounts of an $80 \mathrm{kDa}$ polypeptide (Fig. 1). The PAS-stained bands of corresponding GTF activities (Fig. 1, lanes 5-8) were quantified by laser densitometry. The $80 \mathrm{kDa}$ polypeptide had no GTF activity. The relative enzyme activities for the four strains as estimated from densitometer scans were proportional to the relative activities measured using the radioactive assay for GTF (Table 2).

\section{Effect of $\mathrm{Na}^{+}$concentration and Tween 80}

Increasing the $\left[\mathrm{Na}^{+}\right]$in the growth medium reduced 

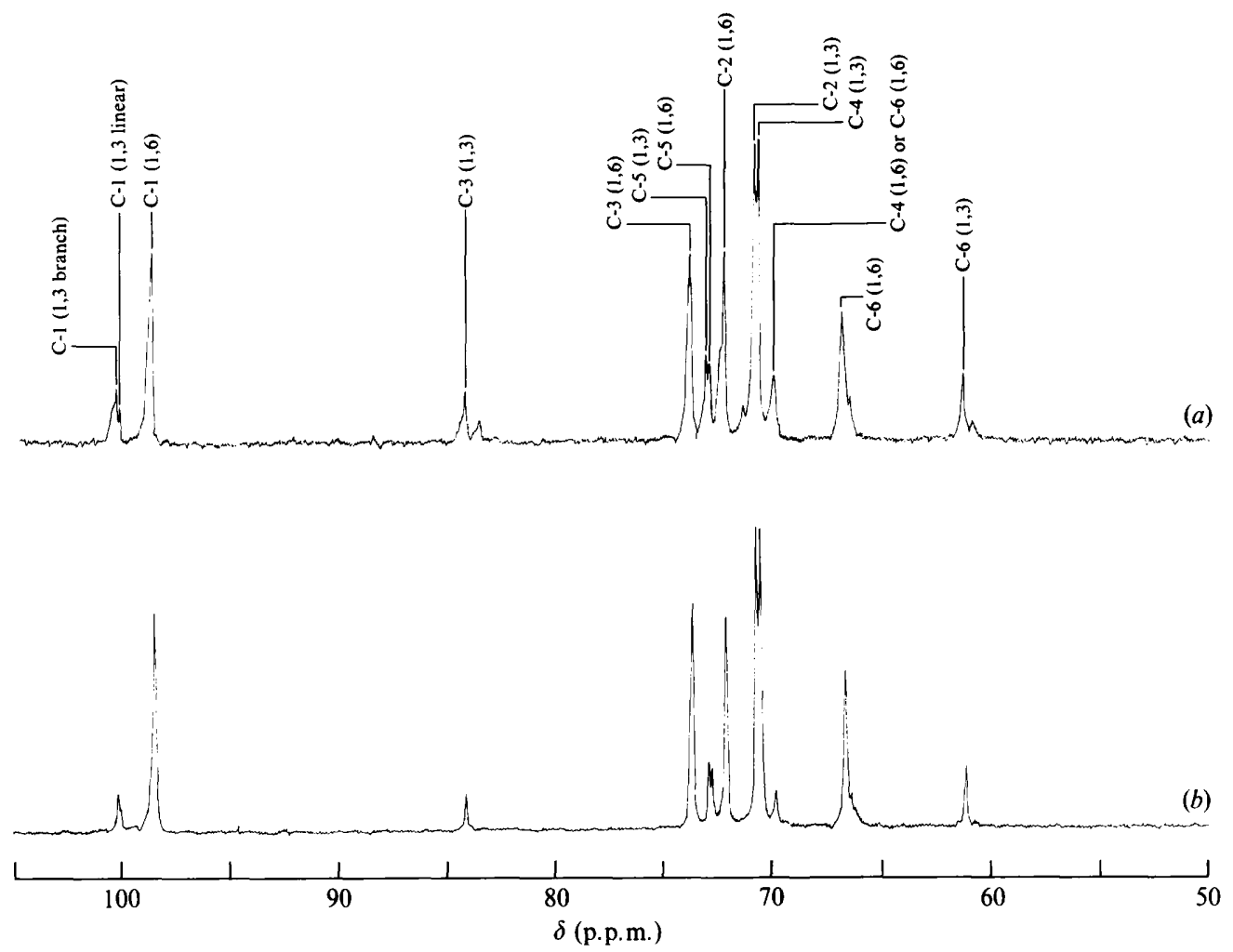

Fig. $2 .{ }^{13} \mathrm{C}$ NMR spectra of $S$. gordonii glucans synthesized by GTF enzymes from strain OB11-Challis $(a)$ and strain OB30 (b). $(1,3)$ refers to $\alpha-1,3$-linked glucose, $(1,6)$ refers to $\alpha$-1,6-linked glucose.

GTF production in strain OB11-Challis and in all mutant strains to about $40 \%$ of the respective levels in the defined medium (low $\left[\mathrm{Na}^{+}\right]$) containing glucose (Table 2). Increased $\left[\mathrm{Na}^{+}\right]$reduced the total amount of protein secreted by all strains, suggesting that this had a general effect on secretion (results not shown). Addition of $0.05 \%$ Tween 80 also inhibited GTF production, but not proportionately in all strains. Tween 80 reduced activity to about $20 \mathrm{mU} \mathrm{m}^{-1}$ for strains OB11-Challis, OB20 and OB30, with OBD3 activity being slightly higher (Table 2). Culture supernatant proteins prepared from cultures grown with Tween 80 were compared by SDS-PAGE. The addition of Tween 80 seemed to have a more-or-less specific effect on reducing production of GTF in all strains (Fig. 1), and on reducing production of the $80 \mathrm{kDa}$ extracellular protein in strains $\mathrm{OB} 30$ and OBD3; it did not reduce overall production of other proteins. The effect of Tween 80 in reducing GTF production in both wild-type and mutant strains to similar levels was also evident on gels activity-stained for GTF (Fig. 1).

Comparison of GTFs and glucans produced by wild-type and mutant strains

The enzyme activities of wild-type and mutant strains were identical in all respects: they had identical $K_{\mathrm{m}}$ values for sucrose $(0.5 \mathrm{mM})$, they were approximately $20 \%$ inhibited by addition of exogenous T10 dextran $\left(50 \mu \mathrm{g} \mathrm{ml}^{-1}\right)$, they showed similar maltose-inhibition profiles (Buchan \& Jenkinson, 1990), and had similar $\mathrm{pH}$ optima (6-6.8). In all strains GTF activities were $80 \%$ inactivated by heating at $70^{\circ} \mathrm{C}$ for $20 \mathrm{~min}$ in $10 \mathrm{~mm}$ sodium acetate/acetic acid buffer $\mathrm{pH}$ 6.0.

Glucans synthesized in vitro by GTF suspensions from wild-type and mutant strains were also compared. Periodate oxidation analyses of the glucans produced by the four strains gave identical results $(2.15 \pm 0.05 \mathrm{~mol}$ periodate consumed per mol formic acid produced). Control experiments with T10 dextran (comprising $99 \%$ $\alpha-1,6$-linked glucose residues) gave a mol periodate $/ \mathrm{mol}$ formate ratio of $2 \cdot 0$. Results from ${ }^{13} \mathrm{C} N M R$ analysis of the glucans produced by GTFs from strains OB11Challis and OB30 are shown in Fig. 2. The chemical shifts and the splits in the peaks for the two glucans were identical. Resonances characteristic of the $\alpha-1,6$-linked glucose backbone were seen in five shifts in each glucan $(98 \cdot 384,73 \cdot 554,72 \cdot 618,71 \cdot 979,66 \cdot 551)$ and resonances at five other shifts associated with $\alpha$-1,3-branching were present (Fig. 2). C-1 resonances characteristic of $\alpha-1,3$ branch- and $\alpha-1,3$ linear-resonances (Colson et al., 1979) could be resolved in both glucans (Fig. 2). 


\section{Discussion}

To begin to investigate the genetic controls operating on GTF production in $S$. gordonii we have isolated mutants that over-produced extracellular polysaccharide. Such mutants were likely to carry mutations in regulatory genes, whereas mutants that are deficient in production of extracellular polysaccharides are more than likely mutated in the structural gene(s) for GTF. The screening method for mutant isolation using CRS agar was developed because it was observed that strains of streptococci had markedly different colony morphologies on this medium. We found that differences in polysaccharide production by streptococcal colonies could be more easily detected on CRS agar than on other media that have been used previously, e.g. Todd-Hewitt broth containing sucrose or Mitis-Salivarius agar (Difco).

The glucan synthesized by $S$. gordonii has been shown to be comprised of mainly $\alpha-1,6$-linked glucose (Hare et al., 1978) with up to $25 \% \alpha-1,3$-linked glucose (Arnett \& Mayer, 1975; Grahame \& Mayer, 1985). The assignments made for the ${ }^{13} \mathrm{C}$ NMR spectrum in Fig. 2 are consistent with this chemical structure. The ${ }^{13} \mathrm{C}$ NMR spectrum of the $S$. gordonii $\mathrm{OB} 11-\mathrm{Challis}$ glucan was almost identical to the spectrum of the 'water-soluble' glucan synthesized by GTF-S from $S$. sobrinus strain C211 (McAlister et al., 1989). Ratios of $\alpha-1,6-$ to $\alpha-1,3-$ linkages (calculated by integration of the signals at 100.048 and 98.384 in Fig. 2) for the $S$. gordonii glucan indicated approximately $20 \% \alpha-1,3$-glycosidic linkages, a value similar to that obtained for the $S$. sobrinus glucan (McAlister et al., 1989). The inference from this work, and from previous work (Grahame \& Mayer, 1985; Buchan \& Jenkinson, 1990), is that $S$. gordonii strains NCTC 7865 and Challis each produce GTF that synthesizes a mixed-linkage glucan. The properties of the mutants described suggest that each overproduces GTF, and that each overproduces a glucan which is structurally identical. No evidence was obtained to suggest that the enzymes from wild-type Challis and mutant strains were different in any respect.

The mutants described carry mutations in loci that control GTF production. Mutant OB20 appeared to over-produce only GTF polypeptide. Mutants OB30 and OBD3, as well as over-producing GTF, also produced an increased amount of another extracellular protein of molecular mass $80 \mathrm{kDa}$ (Fig. 1). Either the $80 \mathrm{kDa}$ protein gene is part of the same operon encoding GTF or the $g t f-30$ mutation affects production of extracellular proteins encoded by genes at separate loci. The second possibility is more likely in view of the fact that the $80 \mathrm{kDa}$ polypeptide was not over-produced by mutant strain OB20. The mutations $g t f-20$ and $g t f-30$ could be transformed into strain DL1-Challis resulting in each case in a phenotype identical to that of the original mutant. This suggests that each phenotype was likely to result from a single mutation. The fact that the mutations could be combined in the one strain, and that the phenotypic effects on GTF production were additive in the double mutant OBD3, further suggested that the mutations were at different loci.

GTF production by all strains was inhibited by increased $\left[\mathrm{Na}^{+}\right]$, which has a general effect on inhibiting protein secretion. However addition of Tween 80 had a different inhibitory effect in that it appeared to abolish the overproduction of GTF by the mutants. We have suggested that $\mathrm{Na}^{+}$and Tween 80 inhibit GTF production in $S$. gordonii Challis by different mechanisms (Buchan \& Jenkinson, 1990) and the results in this paper reinforce this suggestion. If, as it seems likely, the loci defined by $g t f-20$ and $g t f-30$ influence GTF production at the level of transcription, then these mechanisms are sensitive to inhibition by Tween 80 . Recently Tardif $e t$ al. (1989) reported that $S$. gordonii Challis gave rise to colony variants, which were deficient in GTF production, on sucrose-containing medium at a frequency of $10^{-4}$ to $10^{-3}$. When the variants were subcultured they in turn gave rise to 'revertant' colonies, at a frequency of $10^{-4}$ to $10^{-3}$, that again produced GTF. Thus preliminary evidence suggests that GTF production in $S$. gordonii is subject to phase variation, presumably resulting from a genetic switching. Further work is needed to determine if the mutations described in this paper are in any way related to the proposed phaseswitching mechanism. In addition further genetic evidence is needed to determine if there is more than one structural gene encoding GTF in $S$. gordonii.

A Training Fellowship from the Medical Research Council of New Zealand awarded to R. J.H. is gratefully acknowledged. We thank the Department of Chemistry, University of Otago, for use of the NMR spectrometer.

\section{References}

ARNeTt, A. T. \& MAYER, R. M. (1975). Structural characteristics of native and enzymically formed dextran of Streptococcus sanguis ATCC 10558. Carbohydrate Research 41, 339-345.

BUChAN, R. A. \& JENKINSON, H. F. (1990). Glucosyltransferase production by Streptococcus sanguis Challis and comparison with other oral streptococci. Oral Microbiology and Immunology 5, 63-71

Colson, P., JarRell, H. C., LAmberts, B. L. \& Smith, I. C. P. (1979). Determination by carbon-13 nuclear magnetic resonance spectroscopy, of the composition of glucans synthesized by enzymes of the cariogenic organism, Streptococcus mutans. Carbohydrate Research 71, 265-272.

GibBons, R. J. \& VAN Houte, J. (1975). Bacterial adherence in oral microbial ecology. Annual Review of Microbiology 29, 19-44.

Grahame, D. A. \& MAYER, R. M. (1984). The origin and composition of multiple forms of dextransucrase from Streptococcus sanguis. Biochimica et Biophysica Acta 786, 42-48. 
Grahame, D. A. \& Mayer, R. M. (1985). Purification, and comparison, of two forms of dextransucrase from Streptococcus sanguis. Carbohydrate Research 142, 285-298.

HaRe, M. D., Svensson, S. \& WaLKeR, G. J. (1978). Characterization of the extracellular, water-insoluble $\alpha$-D-glucans of oral streptococci by methylation analysis, and by enzymic synthesis and degradation. Carbohydrate Research 66, 245-264.

HaY, G. W., Lewis, B. A. \& SMITH, F. (1965). Periodate oxidation of polysaccharides: general procedures. Methods in Carbohydrate Chemistry 5, 357-360.

JENKINSON, H. F. (1986). Cell-surface proteins of Streptococcus sanguis associated with cell hydrophobicity and coaggregation properties. Journal of General Microbiology 132, 1575-1589.

JENKINSON, H. F. (1987). Novobiocin-resistant mutants of Streptococcus sanguis with reduced cell hydrophobicity and defective in coaggregation. Journal of General Microbiology 133, 1909-1918.

Keevil, C. W., West, A. A., Bourne, N. \& Marsh, P. D. (1984). Inhibition of the synthesis and secretion of extracellular glucosyland fructosyltransferase in Streptococcus sanguis by sodium ions. Journal of General Microbiology 130, 77-82.

Kilian, M., Mixkelsen, L. \& HenRichsen, J. (1989). Taxonomic study of viridans streptococci: description of Streptococcus gordonii sp. nov. and emended descriptions of Streptococcus sanguis (White and Niven 1946), Streptococcus oralis (Bridge and Sneath 1982), and Streptococcus mitis (Andrewes and Horder 1906). International Journal of Systematic Bacteriology 39, 471-484.

LAEMMLI, U. K. \& FAVRE, M. (1973). Maturation of the head of bacteriophage T4. I. DNA packaging events. Journal of Molecular Biology 80, 575-599.

McAlister, D., Nambiar, S., Taylor, K. G. \& Doyle, R. J. (1989). Glucosyltransferases of Streptococcus sobrinus C211 are both stimulated and inhibited by hydrogen peroxide. Oral Microbiology and Immunology 4, 146-152.

Merril, C. R., Goldman, D., Sedmen, S. A. \& Ebert, M. H. (1981). Ultrasensitive stain for proteins in polyacrylamide gels shows regional variation in cerebrospinal fluid proteins. Science 211, 14371438.

Rollins, L. R., LeE, L. N. \& LeBlanc, D. J. (1985). Evidence for a disseminated erythromycin resistance determinant mediated by Tn917-like sequences among group D streptococci isolated from pigs, chickens, and humans. Antimicrobial Agents and Chemotherapy 27, 439-444.

Russell, R. R. B. (1979). Use of Triton X-100 to overcome the inhibition of fructosyltransferase by SDS. Analytical Biochemistry 97 , 173-175.

Sato, S., Ueda, S. \& Kuramitsu, H. K. (1987). Construction of Streptococcus mutans glucosyltransferase mutants utilizing a cloned gene fragment. FEMS Microbiology Letters 48, 207-210.

Scheld, M. W., Valone, J. A. \& SANDe, M. A. (1978). Bacterial adherence in the pathogenesis of endocarditis. Interaction of bacterial dextran, platelets, and fibrin. Journal of Clinical Investigation 61, 1394-1404.

SEYmour, F. R., KNAPP, R. D. \& LAMberTs, B. L. (1980). Unusual dextrans. Structural analysis of soluble D-glucans from strains of Streptococcus mutans by C-13-nuclear magnetic resonance spectroscopy. Carbohydrate Research 84, 187-195.

Schroeder, V. A., Michalek, S. M. \& Macrina, F. L. (1989). Biochemical characterization and evaluation of virulence of a fructosyltransferase-deficient mutant of Streptococcus mutans V403. Infection and Immunity 57, 3560-3569.

Tardif, G., Sulavik, M. C., Jones, G. W. \& Clewell, D. B. (1989). Spontaneous switching of the sucrose-promoted colony phenotype in Streptococcus sanguis. Infection and Immunity 57, 3945-3948.

WalkeR, G. J. \& JACQues, N. A. (1987). Polysaccharides of oral streptococci. In Sugar Transport and Metabolism in Gram-positive Bacteria, pp. 39-68. Edited by J. Reizer \& A. Peterkofsky. Chichester: Ellis Horwood.

West, A. A., Whiley, R. A., Marsh, P. D. \& Keevil, C. W. (1987). The relationship between glucosyltransferase production and membrane fatty acid composition of Streptococcus sanguis NCTC 7865 grown in the presence of protonmotive force inhibitors. Journal of General Microbiology 133, 2601-2606.

WeSTERGREN, G. (1978). Transformation of Streptococcus sanguis to rough colonial morphology with an increased ability to adhere. Archives of Oral Biology 23, 887-891. 